\title{
Itraconazole solid dispersion prepared by a supercritical fluid technique: preparation, in vitro characterization, and bioavailability in beagle dogs
}

This article was published in the following Dove Press journal:

Drug Design, Development and Therapy

28 May 2015

Number of times this article has been viewed

\author{
Xuezhi Yin ${ }^{1,3}$ \\ Linda Sharon Daintree ${ }^{2}$ \\ Sheng Ding ${ }^{3}$ \\ Daniel Mark Ledger ${ }^{2}$ \\ Bing Wang ${ }^{3}$ \\ Wenwen Zhao ${ }^{2}$ \\ Jianping $\mathrm{Q}^{\mathrm{i}}$ \\ Wei Wu'
}

'Department of Pharmaceutics, School of Pharmacy, Fudan University, Key Laboratory of Smart Drug Delivery of Ministry of Education, Shanghai, ${ }^{2}$ Crystec Pharma Tianjin Research Centre, Tianjin, ${ }^{3}$ Changzhou Pharmaceutical Factory, Changzhou, People's Republic of China
Correspondence: Jianping Qi

Department of Pharmaceutics, School of Pharmacy, Fudan University, Key Laboratory of Smart Drug Delivery of Ministry of Education, 826 Zhangheng Road, Pudong New District, Shanghai 201203, People's Republic of China

Tel +86 2I 51980084

Fax +86 21 51980084

Email qijianping@fudan.edu.cn

\begin{abstract}
This research aimed to develop a supercritical fluid (SCF) technique for preparing a particulate form of itraconazole (ITZ) with good dissolution and bioavailability characteristics. The ITZ particulate solid dispersion was formulated with hydroxypropyl methylcellulose, Pluronic F-127, and L-ascorbic acid. Aggregated particles showed porous structure when examined by scanning electron microscopy. Powder X-ray diffraction and Fourier transform infrared spectra indicated an interaction between ITZ and excipients and showed that ITZ existed in an amorphous state in the composite solid dispersion particles. The solid dispersion obtained by the SCF process improved the dissolution of ITZ in media of $\mathrm{pH} 1.0, \mathrm{pH} 4.5$, and $\mathrm{pH}$ 6.8, compared with a commercial product (Sporanox ${ }^{\circledR}$ ), which could be ascribed to the porous aggregated particle shape and amorphous solid state of ITZ. While the solid dispersion did not show a statistical improvement $(P=0.50)$ in terms of oral bioavailability of ITZ compared with Sporanox ${ }^{\circledR}$, the $C_{\max }$ (the maximum plasma concentration of ITZ in a pharmacokinetic curve) of ITZ was raised significantly $(P=0.03)$ after oral administration. Thus, the SCF process has been shown to be an efficient, single step process to form ITZ-containing solid dispersion particles with good dissolution and oral bioavailability characteristics.
\end{abstract}

Keywords: gas anti-solvent, dissolution, HPMC, Pluronic F-127, ascorbic acid, in vivo

\section{Introduction}

Itraconazole (ITZ, Figure 1) is a triazole antifungal agent with a broad spectrum of activity, including activity against a variety of lethal species such as Aspergillus, Candida albicans, and non-Albicans species, and is generally well tolerated. ${ }^{1,2}$ The solubility of ITZ in deionized water is lower than $1 \mathrm{ng} / \mathrm{L}$, whereas its lipophilicity $(\log P>5)$ and permeability across biomembranes are very high, which is typical of class II drugs according to the Biopharmaceutics Classification System. ${ }^{3}$ Because ITZ is a weak base $(\mathrm{pKa}=3.7)$, its aqueous solubility is highly $\mathrm{pH}$ dependent, with approximate saturation solubility of $4 \mu \mathrm{g} / \mathrm{mL}$ at $\mathrm{pH} 1.0$. Thus, ITZ is ionizable and can be only solubilized at low $\mathrm{pH}$ values, for instance, in the stomach. ${ }^{4}$ The oral bioavailability and clinical efficacy of ITZ is significantly compromised mainly due to its extremely poor water solubility. The low dissolution rate is the rate-limiting step in ITZ absorption from the gastrointestinal tract. There is a demand to improve the dissolution of ITZ so as to enhance its oral bioavailability.

Various techniques have been used to improve the solubility of poorly water-soluble drugs, including using surfactants, ${ }^{5}$ inclusion complexation, ${ }^{6,7}$ and solid dispersion (SD) techniques. ${ }^{8}$ For example, the SD technique has been well used to enhance 


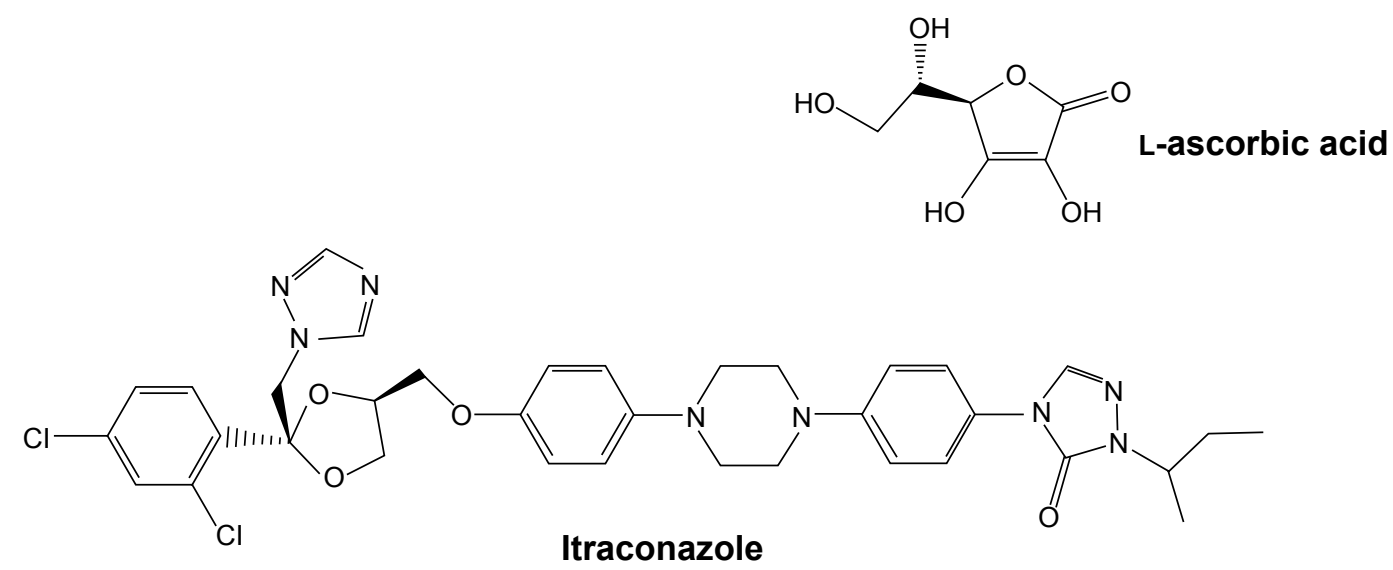

Figure I The chemical structures of itraconazole and L-ascorbic acid.

the dissolution rate of ITZ, ${ }^{4,8-10}$ and one of the commercial products of ITZ (Sporanox ${ }^{\circledR}$ ) is a hard capsule form containing ITZ coated on sugar spheres. Drug was layered onto the sugar pellets by the fluid bed-based SD technique using hydroxypropyl methylcellulose (HPMC) as the hydrophilic dispersing material. ${ }^{11}$ Drugs in SDs may exist in the fine crystalline or amorphous form, which achieves a highly dispersed state in polymeric carriers. In comparison with common crystalline drugs, SDs can achieve the highest levels of particle size reduction and surface area enhancement, all directly related to the improved solubility and dissolution rate according to the Noyes-Whitney dissolution equation. ${ }^{12}$ The most commonly used SD carriers are highly hydrophilic polymers such as polyethylene glycols, HPMCs, poloxamers, and polyvinylpyrrolidones. ${ }^{10,13}$ To reinforce the dissolution rate or the physical stability of dispersed drug entities in the carrier matrix, additives such as surfactants or $\mathrm{pH}$ modulators can also be used. ${ }^{8,14,15}$ It was reported earlier that the oral bioavailability of ITZ could be enhanced by coadministration with a vitamin $\mathrm{C}$ beverage in healthy participants. ${ }^{16}$ Vitamin C (L-ascorbic acid, LAA), a highly acidic material, is an essential micronutrient involved in many biological and biochemical functions (Figure 1). LAA is expected to form an acidic microenvironment when coincorporated with the drug into the carrier matrix, which would further facilitate the dissolution rate of ITZ from the SD. Therefore, in this study, LAA was used as a $\mathrm{pH}$ modulator in SDs with the aim to improve the dissolution and in vivo performance of ITZ.

In general, SDs can be prepared by the melting/ congealing method, the solvent evaporation method, or the cogrinding method. ${ }^{17-21}$ However, each method has its own pros and cons. In the melting method, drug entities must be unavoidably exposed to very high temperature, which is detrimental to heat-sensitive drugs; moreover, there is difficulty in pulverizing the congealed melts owing to their relatively soft nature. ${ }^{17}$ Although the solvent evaporation method can be carried out at relatively lower temperatures, a large amount of organic solvent should be used to solubilize both the drug and the polymers, which thus imposes problems of safety concerns, high costs, and residual solvent removal. ${ }^{22}$ The cogrinding method consumes a lot of energy, and the dispersion efficiency is quite low. ${ }^{20}$ Recently, the supercritical fluid (SCF) technique has been proposed as an alternative for formulating SDs with distinct features of operating at lower temperature to avoid heat decomposition, lower residual organic solvent, and one-step production of powders with better flowability. ${ }^{22-24}$ In the SCF process, liquid carbon dioxide $\left(\mathrm{CO}_{2}\right)$ is used as the antisolvent, which leads to the precipitation of the substrates initially dissolved in the organic solvent. ${ }^{22,25,26}$ Certain aspects of this technology can be found in the works of other groups. ${ }^{12,23,24}$ Meanwhile, some studies also reported the use of SCF technology to obtain nanoscale-level SD particles or drug-polymer aggregates to improve the solubility and oral bioavailability of ITZ..$^{27,28}$

In this study, ITZ SD particles, with LAA as a pH modulator, as well as HPMC and Pluronic F-127 (F127) as carriers, were prepared by a gas antisolvent process and characterized using powder X-ray diffraction (PXRD), Fourier transform infrared (FT-IR) spectrometry, and scanning electron microscopy (SEM). The dissolution and oral bioavailability of ITZ SD particles were then investigated and compared with those of commercial Sporanox ${ }^{\circledR}$ (Janssen Pharmaceuticals Inc).

\section{Materials and methods Materials}

ITZ was purchased from Shouguang Fukang Pharmaceutical Co, Ltd (Jinan, People's Republic of China). LAA was obtained from Tianjin Guangfu Fine Chemical Research Institute (Tianjin, People's Republic of China). HPMC (3.23 mPa.s), F127, and hard gelatin capsules (clear, size 00) 
were purchased by Sigma-Aldrich (St Louis, MO, USA). Warfarin was provided by the Central Research Institute, Shanghai Pharmaceuticals Holding Co, Ltd (Shanghai, People's Republic of China). High-performance liquid chromatography (HPLC)-grade methanol was purchased from Tedia (Fairfield, $\mathrm{OH}, \mathrm{USA}$ ). $\mathrm{CO}_{2}$ (purity: 99.9\%) was obtained from Huaming Gas Sales Co, Ltd (Tianjin, People's Republic of China). Dichloromethane (analytical grade) was purchased from Sinopharm Chemical Reagent Co, Ltd (Shanghai, People's Republic of China). Deionized water was prepared using a Milli-Q purification system (Millipore, Billerica, MA, USA). All other chemicals were of analytical grade and used as received.

\section{Preparation of ITZ SD particles}

In this study, Crystec Ltd proprietary, modified supercritical antisolvent rigs were used to produce ITZ SD particles. ${ }^{29}$ Briefly, ITZ (0.72 g) and LAA (0.18 g) were dissolved in $12 \mathrm{~mL}$ mixed solvents of methanol and dichloromethane $(1: 1, \mathrm{v} / \mathrm{v})$ with the aid of sonication. HPMC $(0.81 \mathrm{~g})$ and F127 $(0.09 \mathrm{~g})$ were dissolved in $12 \mathrm{~mL}$ of dichloromethane. These two solutions were then mixed together to form a solution whose total solid concentration (including ITZ, LAA, HPMC, and $\mathrm{F} 127)$ was $7.5 \%(\mathrm{w} / \mathrm{v})$ and the final ratio of methanol to dichloromethane was $1: 3(\mathrm{v} / \mathrm{v})$. The mixed solution was fed with supercritical $\mathrm{CO}_{2}$ through a specially designed nozzle into a particle formation vessel $(200 \mathrm{~mL}$ and $2 \mathrm{~L}$ at laboratory and pilot plant scales) under stable conditions of temperature $\left(50^{\circ} \mathrm{C} \pm 1^{\circ} \mathrm{C}\right)$ and pressure (95 bars $\left.\pm 0.5 \%\right)$. The SCF dispersed, mixed with, and rapidly extracted the solvent, leading to the formation of SD particles, which were collected in the vessel. It is well reported that supercritical $\mathrm{CO}_{2}$ is an excellent scavenger of solvent. ${ }^{30}$ Thermogravimetric analysis of SD powder showed no weight loss due to residual solvent. By manipulating the working conditions of pressure, temperature, solution concentration, and flow rate in the nozzle, it was possible to control the size, shape, and morphology of the products. SD particles were produced from a 7.5\% methanol/ dicholoromethane $(1: 3, \mathrm{v} / \mathrm{v})$ solution at $50^{\circ} \mathrm{C}$ and $95 \mathrm{bars}$, and the flow rate of $\mathrm{CO}_{2}$ and organic solution was $20 \mathrm{~mL} / \mathrm{min}$ and $0.4 \mathrm{~mL} / \mathrm{min}$, respectively. The SCF process for the preparation of ITZ SD particles is shown in Figure 2.

\section{Characterization of SD particles}

The samples, including ITZ, LAA, HPMC, F127, physical mixture, and SD particles, were characterized by PXRD, SEM, and FT-IR. The physical mixture was prepared by mixing the ITZ (0.72 g), LAA (0.18 g), HPMC (0.81 g), and F127 (0.09 g), which is the same as the constituents comprising the SD particles.

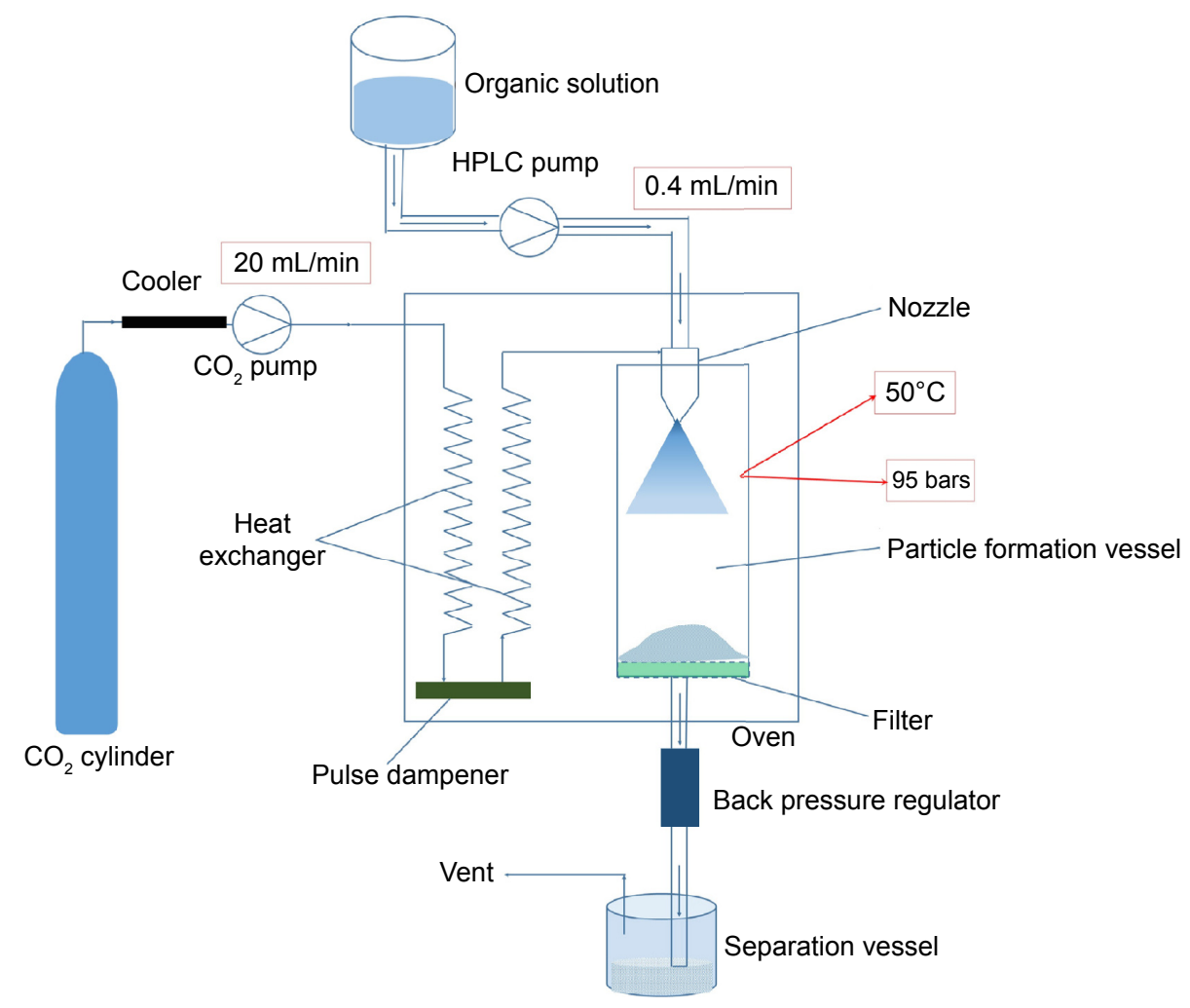

Figure 2 The schematic diagram of the supercritical fluid process. 


\section{Powder X-ray diffraction}

PXRD of the samples was performed using an X-ray polycrystalline diffractometer (D8 Advance; Bruker, Karlsruhe, Germany) over the $2^{\circ}-40^{\circ} 2 \theta$ range at a scan rate of $2^{\circ} / \mathrm{min}$, wherein the tube anode was $\mathrm{Cu}$ with $\mathrm{K} \alpha=0.154 \mathrm{~nm}$, monochromatized with a graphite crystal. The pattern was collected with $40 \mathrm{kV}$ of tube voltage and $40 \mathrm{~mA}$ of tube current in the step scan mode (step size: $0.02^{\circ}$; counting time: 0.6 seconds per step).

\section{Scanning electron microscopy}

SEM was used to characterize the morphology, size distribution, and degree of agglomeration of the particles. The samples (ITZ, LAA, HPMC, F127, and SD particles) were fixed with conductive double-sided adhesive carbon tape and sputter coater with gold coating under vacuum. Finally, the photographs were taken at an excitation voltage of $10 \mathrm{kV}$ by a scanning electron microscope (LEO $1530 \mathrm{VP}$; Zeiss, Oberkochen, Germany).

\section{Fourier transform infrared spectrometry}

FT-IR spectra were obtained on a Nexus 870 spectrometer (Nicolet, Madison, WI, USA). The samples were mixed with $\mathrm{KBr}$ thoroughly, an IR-transparent matrix, and compressed into disks. The scans were obtained from $4,000 \mathrm{~cm}^{-1}$ to $400 \mathrm{~cm}^{-1}$ at a resolution of $4 \mathrm{~cm}^{-1}$.

\section{In vitro dissolution}

The dissolution test was performed using a RCZ-8B dissolution tester (Tianda Tianfa Technology Co, Ltd, Tianjin, People's Republic of China) according to the Chinese Pharmacopoeia, Appendix X Method 2, with the paddle apparatus. SD particles equivalent to $100 \mathrm{mg}$ ITZ filled into capsules were immersed into $1,000 \mathrm{~mL}$ of dissolution medium, which was thermostatically maintained at $37^{\circ} \mathrm{C} \pm 0.5^{\circ} \mathrm{C}$ and stirred at a revolution speed of $75 \mathrm{rpm}$, with Sporanox ${ }^{\circledR}(100 \mathrm{mg}$ ITZ) capsule as a reference. To perform stricter evaluation, three different dissolution media were used, ie, $0.1 \mathrm{M}$ hydrochloric acid solution ( $\mathrm{pH} 1.0$ ), $0.02 \mathrm{M}$ acetate buffer solution ( $\mathrm{pH} 4.5$ ), and $0.05 \mathrm{M}$ phosphate buffer solution (pH 6.8). Aliquots of samples $(10 \mathrm{~mL})$ were withdrawn at different time intervals ( 5 minutes, 10 minutes, 15 minutes, 20 minutes, 30 minutes, 45 minutes, 60 minutes, and 90 minutes) and filtered through a $0.45 \mu \mathrm{m}$ membrane. The filtrate was diluted five times with a mixture of methanol and dissolution medium $(5: 95, \mathrm{v} / \mathrm{v})$, and was then analyzed with a TU-1810 ultraviolet spectrophotometer (Beijing Purkinje General Instrument Co, Ltd, People's Republic of China) at $255 \mathrm{~nm}$. Measurements were conducted in triplicate.

\section{Oral bioavailability in beagle dogs}

The oral bioavailability of ITZ SD particles was evaluated in beagle dogs, with marketed Sporanox ${ }^{\circledR}$ capsule as the reference. Beagle dogs (adult male, $11.5 \pm 0.5 \mathrm{~kg}$ ) used in the experiments received care in compliance with the Principles of Laboratory Animal Care and the Guide for the Care and Use of Laboratory Animals. The experimental study protocol was approved by the Fudan University Institutional Animal Ethics Committee (number 20120426).

ITZ SD particles and Sporanox ${ }^{\circledR}$ were divided into two groups and respectively administered to three dogs by oral gavage at an equivalent dose of $8.7 \mathrm{mg} / \mathrm{kg}$ ITZ. Blood samples $(2 \mathrm{~mL})$ were then collected into heparinized tubes at designated time intervals -0.5 hours, 1.0 hours, 1.5 hours, 2.0 hours, 3.0 hours, 4.0 hours, 5.0 hours, 6.0 hours, 7.0 hours, 9.0 hours, 12 hours, 24 hours, and 48 hours. Plasma was separated by centrifugation for 10 minutes at $3,200 \times g$ and frozen at $-20^{\circ} \mathrm{C}$ until analysis.

The blood sample was processed as follows: $100 \mu \mathrm{L}$ plasma was mixed, by vortexing, with $500 \mu \mathrm{L}$ of a methanol solution of warfarin (internal standard, $50 \mathrm{ng} / \mathrm{mL}$ ) in a $1.5 \mathrm{~mL}$ centrifuge tube for 1 minute. The mixture was centrifuged at $10,000 \times g$ for 10 minutes. The supernatant $(100 \mu \mathrm{L})$ was withdrawn, mixed with an equal volume of water, and then $5 \mu \mathrm{L}$ was injected into the liquid chromatography-tandem mass spectrometry (LC-MS/MS) system.

\section{Determination of ITZ in plasma by HPLC-MS/MS}

The concentration of ITZ in dog plasma was determined by an HPLC-MS/MS method previously reported, with modifications. ${ }^{31}$ Chromatographic separation was performed on an Agilent 1100 system, which was composed of a quaternary pump, a degasser, an autosampler, and a column heater. The HPLC column was Agela Venusil XBP Phenyl column $(100 \mathrm{~mm} \times 2.1 \mathrm{~mm}, 5 \mu \mathrm{m})$. The mobile phase consisted of methanol/water (containing $2 \mathrm{mM}$ ammonium acetate and $0.1 \%$ formic acid) at a ratio of $85: 15(\mathrm{v} / \mathrm{v})$ with a flow rate of $0.40 \mathrm{~mL} / \mathrm{min}$. The column temperature was set at $40^{\circ} \mathrm{C}$. An API-4000 mass spectrometer with an electrospray ionization ion source (Applied Biosystems Co, Waltham, MA, USA) was used for the detection of ITZ. Parent and daughter ions of ITZ were at mass-to-charge ratio $(\mathrm{m} / \mathrm{z}) 705.2$ and $\mathrm{m} / \mathrm{z}$ 392.2 , respectively; parent and daughter ions of the internal standard (warfarin) were at $\mathrm{m} / \mathrm{z} 309.1$ and $\mathrm{m} / \mathrm{z} 163.2$, respectively. Collision energy for ITZ and warfarin was $49 \mathrm{~V}$ and $20 \mathrm{~V}$, respectively. Ion spray voltage was set at $5,000 \mathrm{~V}$, while temperature was set at $500^{\circ} \mathrm{C}$. The flow rates of ion 
source gases 1 and 2 were individually set to $50 \mathrm{~L} / \mathrm{min}$ and $60 \mathrm{~L} / \mathrm{min}$, respectively.

Method validation results gave linearity of $20-1,000 \mathrm{ng} / \mathrm{mL}$, with a typical calibration curve of $y=0.000186 x-0.000379$ $\left(R^{2}=0.9989, \mathrm{n}=6\right)$. The accuracies at $20 \mathrm{ng} / \mathrm{mL}, 100 \mathrm{ng} / \mathrm{mL}$, and $1,000 \mathrm{ng} / \mathrm{mL}$ were $110.08 \% \pm 2.27 \%, 96.32 \% \pm 1.59 \%$, and $102.42 \% \pm 8.54 \%$, respectively; the inter- and intraday precisions were all below $6.38 \%$. Samples of concentrations $>1,000 \mathrm{ng} / \mathrm{mL}$ were diluted before analysis. The stability test indicated that the concentration of ITZ in the plasma sample stored at $-20^{\circ} \mathrm{C}$ remained stable over a 30-day period.

\section{Statistical analysis}

All data were expressed as mean \pm standard deviation. Student's $t$-test was performed to assess the statistical significance of differences using Sigmastat (version 3.5). Results with $P<0.05$ were considered statistically significant.

\section{Results and discussion Preparation and characterization of ITZ SD particles}

Figure 3 shows the surface morphology of SD particles, ITZ, and all excipients used. The ITZ raw materials are rod-like
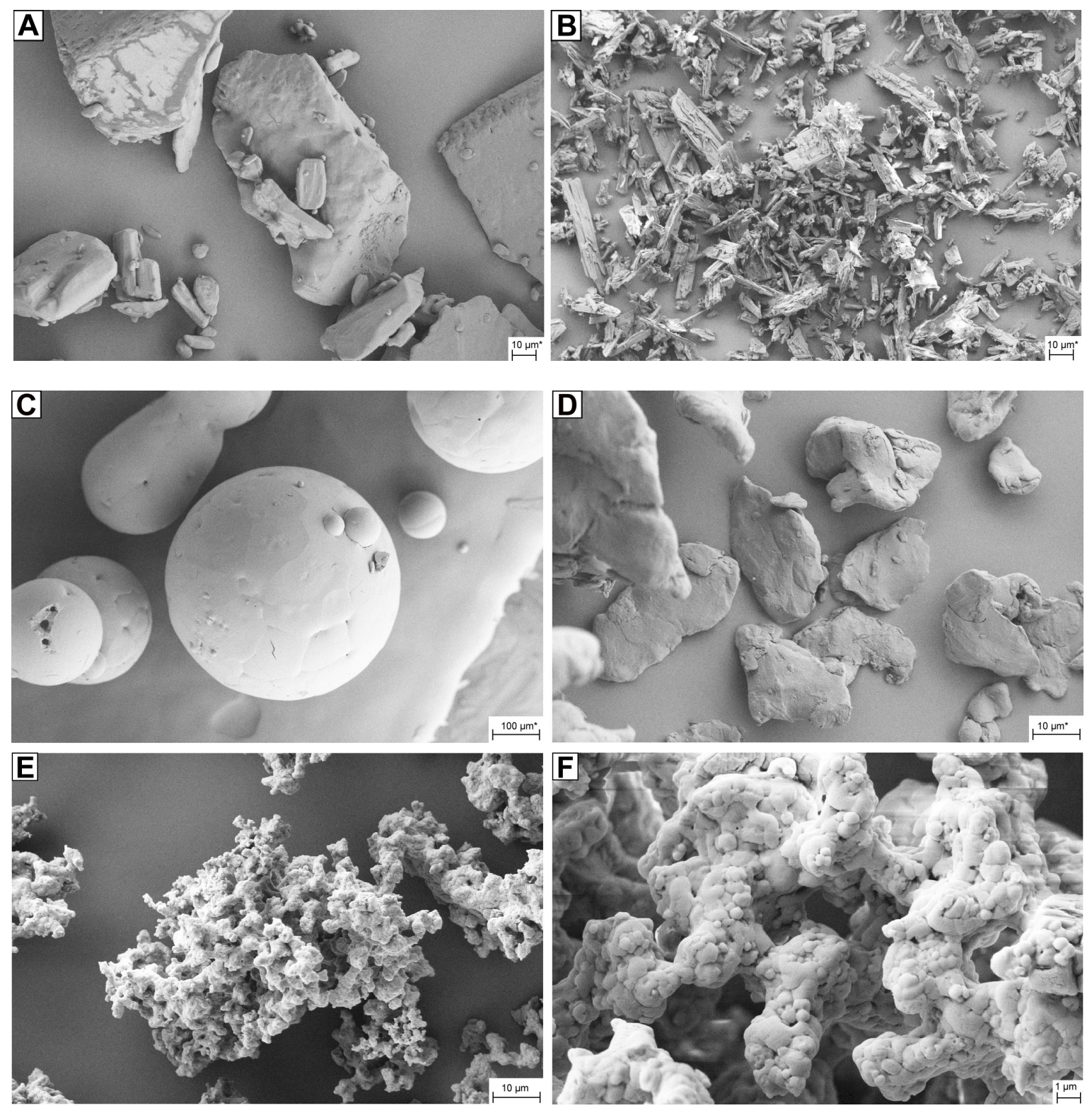

Figure 3 The surface morphology of LAA (A), ITZ (B), FI27 (C), HPMC (D), SD particles (E and F) observed by SEM.

Abbreviations: LAA, L-ascorbic acid; ITZ, itraconazole; FI27, Pluronic F-I27; HPMC, hyproxypropyl methylcellulose; SD, solid dispersion; SEM, scanning electron microscopy. 
crystals with various sizes, and LAA shows irregular morphology. In contrast, the composite SD particles are porous aggregates, composed of numerous small-sized spherical particles, a feature similar to previously reported composite particles prepared using SCF-based processes. ${ }^{22}$ Meanwhile, the ITZ crystal forms and shapes of all the excipients disappeared in the SD particles, which indicated that ITZ could exist in the amorphous form.

The PXRD patterns of ITZ, excipients, physical mixtures, and SD particles are shown in Figure 4. The PXRD pattern for ITZ raw material showed several characteristic peaks within the $2 \theta$ range from $10^{\circ}$ to $30^{\circ}$, such as intensive absorption peaks at $14.48^{\circ}, 17.48^{\circ}, 20.38^{\circ}$, and $22.36^{\circ}$. Moreover, the LAA PXRD pattern showed numerous characteristic peaks within the $2 \theta$ range from $10^{\circ}$ to $40^{\circ}$. The F127 PXRD pattern showed two characteristic peaks in the $2 \theta$ range at $17^{\circ}$ and $23^{\circ}$ approximately, whereas the HPMC pattern was typical of an amorphous material with no characteristic peaks, which is the nature of a polymer. ${ }^{32}$ The PXRD of the physical mixture showed the characteristic peaks of ITZ, F127, and LAA within the $2 \theta$ range from $10^{\circ}$ to $40^{\circ}$. However, all of the distinct peaks disappeared in the SD particles' diffractogram, which indicated that the crystal form did not exist in the SD particles. ${ }^{28}$ This result suggested that ITZ might exist in the amorphous state in SD particles, as frequently observed for SDs.

It could be seen that the SD particles demonstrate a similar FT-IR spectrum to that of ITZ (Figure 5), while there are some minor variations between them. For instance, LAA showed absorption peaks at $3,316 \mathrm{~cm}^{-1}$ and $3,217 \mathrm{~cm}^{-1}$, which belonged to the $\mathrm{C}=\mathrm{C}-\mathrm{OH}$ group of LAA. ITZ showed

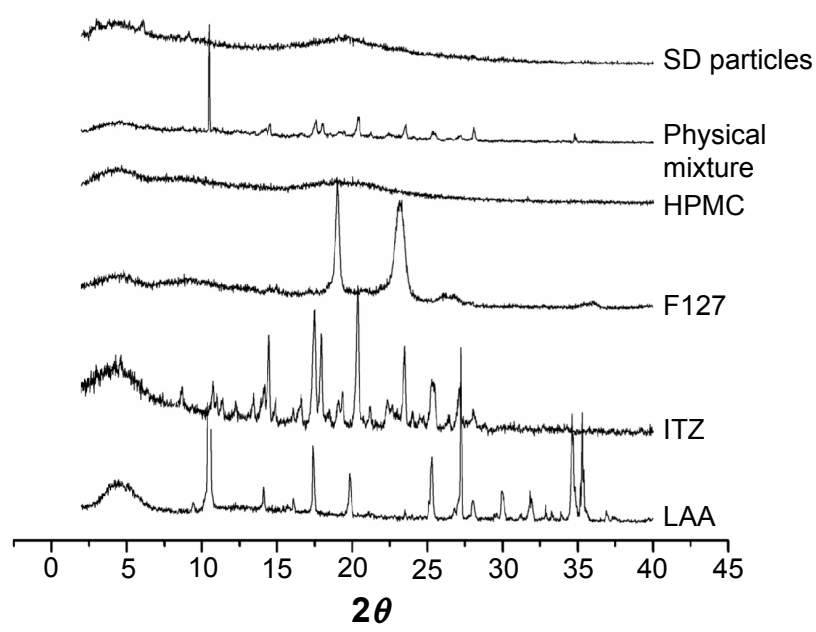

Figure 4 The powder X-ray diffractograms of LAA, ITZ, FI27, HPMC, and SD particles.

Abbreviations: LAA, L-ascorbic acid; ITZ, itraconazole; FI27, Pluronic F-127; HPMC, hyproxypropyl methylcellulose; SD, solid dispersion. absorption peaks at $3,461 \mathrm{~cm}^{-1}$, which belonged to the $\mathrm{N}=\mathrm{CH}-\mathrm{N}$ group. These peaks remained in the spectrum of the physical mixture, whereas they disappeared in the spectrum for SD particles. It was reasonable to conclude that a hydrogen bond had been formed between the $\mathrm{C}=\mathrm{C}-\mathrm{OH}$ group of LAA and the triazole group of ITZ.

\section{In vitro dissolution}

The dissolution profiles of ITZ in solutions at $\mathrm{pH} 1.0, \mathrm{pH} 4.5$, and $\mathrm{pH} 6.8$ are shown in Figure 6. The results indicated that, as expected, the dissolution of ITZ was $\mathrm{pH}$ dependent. More than $90 \%$ dissolution of ITZ was observed within 60 minutes in a medium of $\mathrm{pH} 1.0$ for not only SD particles but also Sporanox $^{\circledR}$, while the dissolution was $<25 \%$ in $\mathrm{pH} 4.5$ and $\mathrm{pH} 6.8$ media for the two formulations. However, faster dissolution was observed up to 45 minutes in $\mathrm{pH} 1.0$ for SD particles than for Sporanox ${ }^{\circledR}$, and the dissolution of ITZ from SD particles was faster than that from Sporanox ${ }^{\circledR}$ over this period.

The rapid dissolution of ITZ in $\mathrm{pH} 1.0$ medium was ascribed to its alkaline nature. ${ }^{4}$ The aggregated primary SD particles could be readily penetrated by water to a greater extent and disintegrated more rapidly than the Sporanox ${ }^{\circledR}$ pellets due to their porous surfaces, which led to faster dissolution for up to 45 minutes. This suggested that the surface morphology of SDs might also be a critical factor for improving the dissolution of poorly soluble drugs. In addition, the LAA in SD particles could maintain the local acidic environment during the dissolution process, which contributed to enhanced dissolution of ITZ from SD particles in media of $\mathrm{pH} 4.5$ and $\mathrm{pH}$ 6.8. However, the dissolution profiles in $\mathrm{pH} 4.5$ and $\mathrm{pH} 6.8$ media showed a reducing tendency after 45 minutes. Thus, it is proposed that the local acidic environment generated by LAA enhanced the formation of supersaturated solution of ITZ in the early stages of dissolution, up to 45 minutes, which was followed by some recrystallization of ITZ at longer dissolution-testing times. ${ }^{33}$

\section{Oral bioavailability}

The plot of mean plasma concentration of ITZ versus time is given in Figure 7, and the pharmacokinetic parameters are shown in Table 1. There were similar profiles of plasma ITZ concentration versus time observed for both ITZ SD particles and Sporanox ${ }^{\circledR}$. However, ITZ demonstrated rapid absorption and significantly $(P<0.05)$ higher $C_{\text {max }}$ (the maximum plasma concentration of ITZ in a pharmacokinetic curve) after oral administration of SD particles (423.67 \pm $61.27 \mathrm{ng} / \mathrm{mL})$ than Sporanox ${ }^{\circledR}(305.33 \pm 10.79 \mathrm{ng} / \mathrm{mL})$. After 


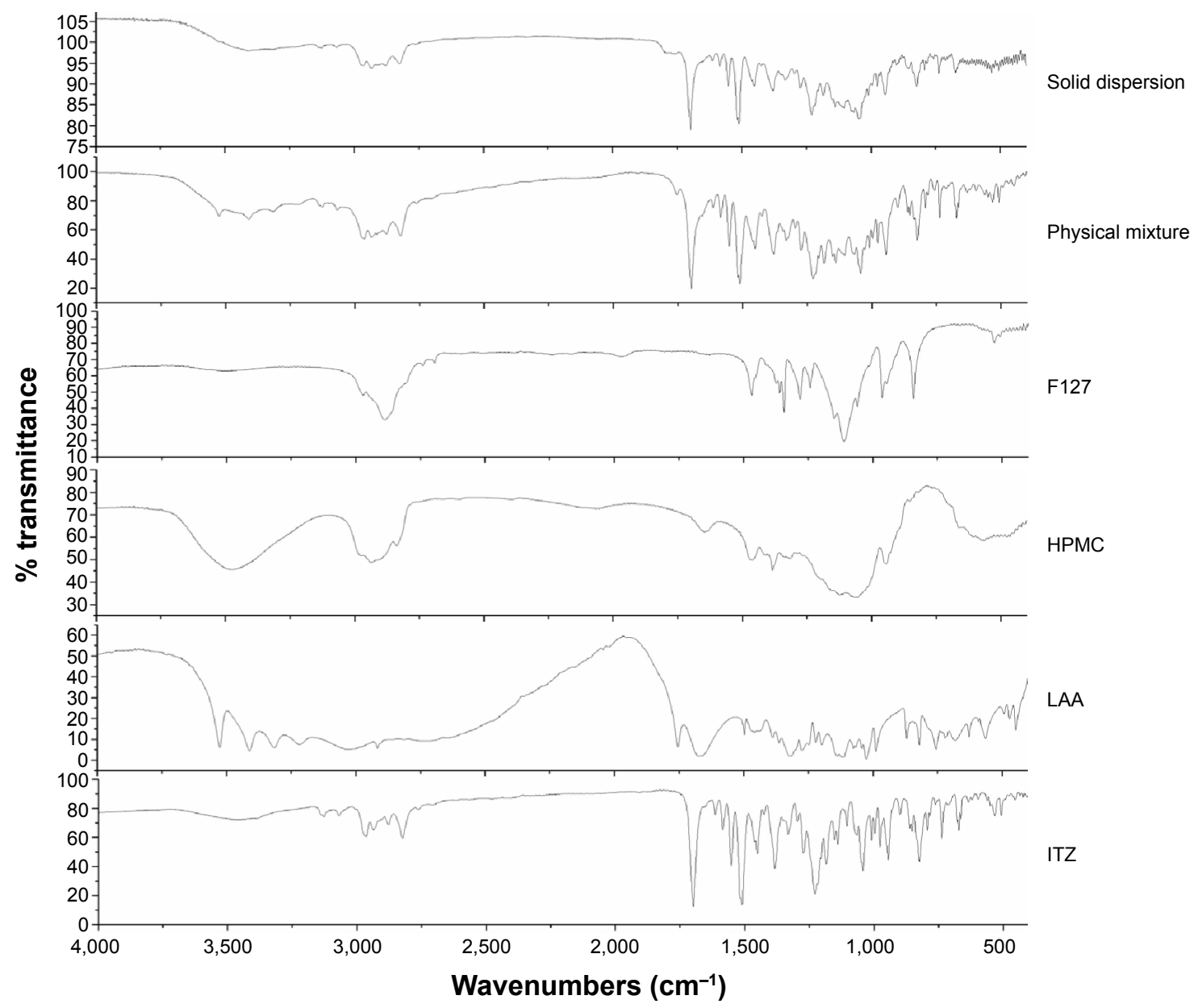

Figure 5 The FT-IR spectra of LAA, ITZ, FI27, HPMC, and SD particles.

Abbreviations: FT-IR, Fourier transform infrared; LAA, L-ascorbic acid; ITZ, itraconazole; FI27, Pluronic F-127; HPMC, hyproxypropyl methylcellulose; SD, solid dispersion.

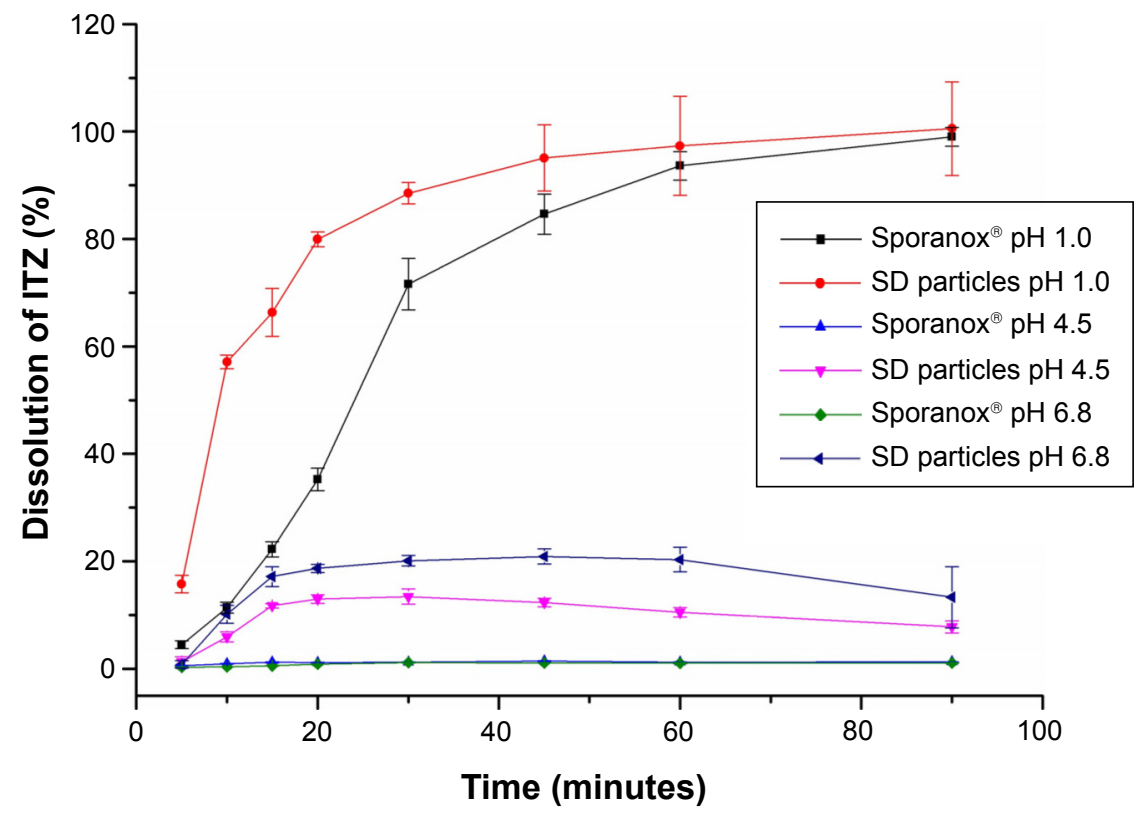

Figure 6 The dissolution profiles of SD particles and Sporanox ${ }^{\circledast}$ in media of $\mathrm{pH}$ 1.0, $\mathrm{pH} 4.5$, and pH $6.8(\mathrm{n}=6)$.

Note: Data represented as mean \pm standard deviation.

Abbreviations: ITZ, itraconazole; SD, solid dispersion. 


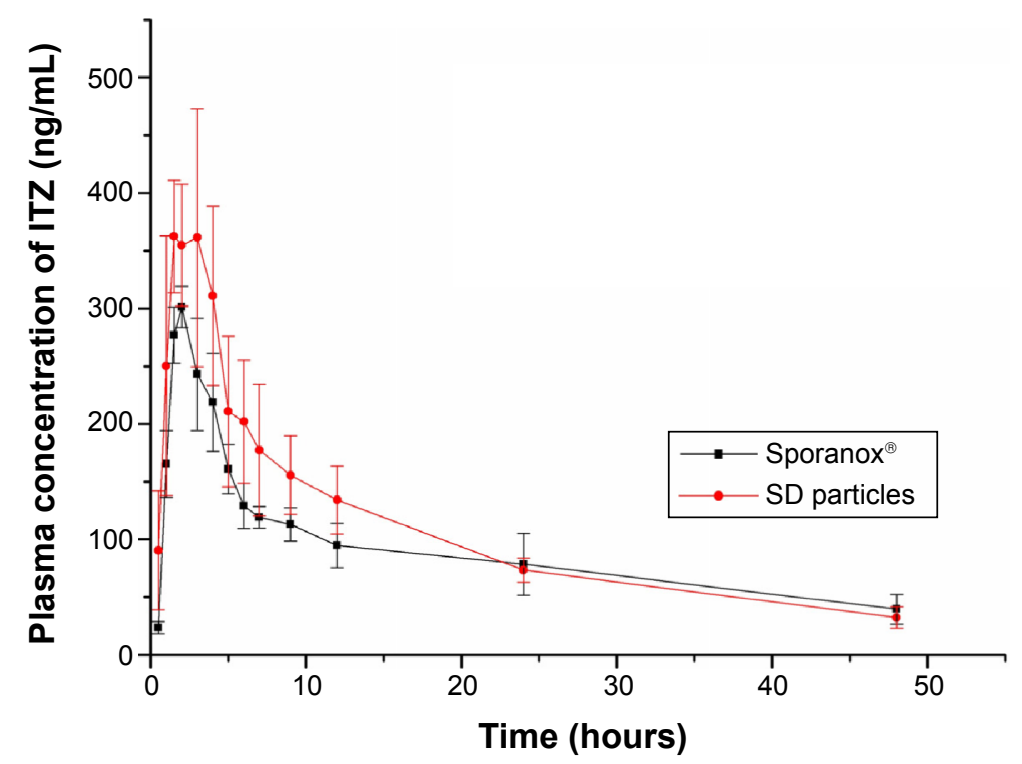

Figure 7 The plots of mean plasma concentration versus time for itraconazole in beagle dogs after oral administration of SD particle capsules and $\mathrm{Sporanox}{ }^{\circledR}$ ( $\mathrm{n}=3$ ). Note: Data represented as mean \pm standard deviation.

Abbreviations: ITZ, itraconazole; SD, solid dispersion.

oral administration of SD particles, the relative bioavailability of ITZ was $120 \%$ in comparison with Sporanox ${ }^{\circledR}$, but with no statistical significance. However, the $T_{\max }$ (the time when the plasma concentration of ITZ reaches the peak in the pharmacokinetic curve) and mean retention time showed no significant difference between SD particles and Sporanox ${ }^{\circledR}$.

Considering the evidence obtained from the in vitro dissolution test, it was hypothesized that the more rapid dissolution of ITZ from SD particles than from Sporanox ${ }^{\circledR}$ led to higher $C_{\max }$ due to its high permeability across intestinal epithelia. ${ }^{3}$ However, the improvement of dissolution in media of $\mathrm{pH} 4.5$ and $\mathrm{pH} 6.8$ has not increased oral bioavailability significantly. There are several possible explanations for the poor predictability of the extent of oral drug absorption based on the in vitro dissolution data. The ITZ dissolved in the stomach might have precipitated as it passed into the small intestine because the solubility of ITZ is reduced drastically as the $\mathrm{pH}$ increases. ${ }^{4}$ Therefore, in vitro dissolution at $\mathrm{pH} 4.5$ and pH 6.8 does not reflect the in vivo biological environments and effects in this case. Although some reports also suggest that the presence of some organic acids (citric acid) in SDs of ITZ will enhance drug dissolution or bioavailability, ${ }^{8}$ LAA did not demonstrate any influence in enhancing in vivo bioavailability.

\section{Conclusion}

ITZ SD particles were obtained by a one-step SCF-based antisolvent process. PXRD and FT-IR were used to characterize the physical properties of SD particles. The morphology of SD particles obtained by SCF showed a porous structure with aggregated particles composed of micron-sized primary particles. The SD particles showed improved dissolution of ITZ in media of $\mathrm{pH} 1.0, \mathrm{pH} 4.5$, and $\mathrm{pH} 6.8$ in comparison with Sporanox ${ }^{\circledR}$. The bioavailability after oral administration of SD particles showed no significant increase compared with that of Sporanox ${ }^{\circledR}$; however, the $C_{\max }$ was raised significantly $(P=0.03)$ after oral administration of SD particles. In conclusion, the SCF technique has been shown to be a suitable and attractive single-step process for preparing SD particles of ITZ.

Table I The main pharmacokinetic parameters of itraconazole in beagle dogs after oral administration of SD particles capsules and Sporanox ${ }^{\circledR}(n=3)$

\begin{tabular}{llll}
\hline & SD particles & Sporanox $^{\circledast}$ & Fold change \\
\hline $\mathrm{AUC}_{0 . \mathrm{t}}(\mathrm{ng} / \mathrm{mL} \cdot \mathrm{h})$ & $4,663.31 \pm 1,428.38$ & $3,895.58 \pm 1,092.81$ & 1.20 \\
$C_{\max }(\mathrm{ng} / \mathrm{mL})$ & $423.67 \pm 61.27^{*}$ & $305.33 \pm 10.79$ & 1.39 \\
$T_{\max }($ hours $)$ & $2.17 \pm 0.76$ & $1.83 \pm 0.29$ & 1.19 \\
$\mathrm{MRT}_{0-\mathrm{t}}$ (hours) & $12.36 \pm 2.74$ & $14.56 \pm 5.24$ & 0.86 \\
\hline
\end{tabular}

Notes: Values are presented as mean \pm standard deviation. $* P<0.05$ compared with Sporanox.

Abbreviations: AUC, area under the curve; $C_{\text {max }}$, the maximum plasma concentration of ITZ in a pharmacokinetic curve; ITZ, itraconazole; MRT, mean retention time; SD, solid dispersion; $T_{\max }$, the time when the plasma concentration of ITZ reaches the peak in the pharmacokinetic curve. 


\section{Disclosure}

The authors report no conflicts of interest in this work.

\section{References}

1. De Beule K, Van Gestel J. Pharmacology of itraconazole. Drugs. 2001;61:27-37.

2. Lestner J, Hope WW. Itraconazole: an update on pharmacology and clinical use for treatment of invasive and allergic fungal infections. Expert Opin Drug Metab Toxicol. 2013;9(7):911-926.

3. Peeters J, Neeskens P, Tollenaere JP, Van Remoortere P, Brewster ME. Characterization of the interaction of 2-hydroxypropyl-beta-cyclodextrin with itraconazole at $\mathrm{pH}$ 2, 4, and 7. J Pharm Sci. 2002;91(6): 1414-1422.

4. Zhang K, Yu H, Luo Q, et al. Increased dissolution and oral absorption of itraconazole/soluplus extrudate compared with itraconazole nanosuspension. Eur J Pharm Biopharm. 2013;85(3):1285-1292.

5. Janssens S, Van Humbeeck J, Van den Mooter G. Evaluation of the formulation of solid dispersions by co-spray drying itraconazole with Inutec SP1, a polymeric surfactant, in combination with PVPVA 64. Eur J Pharm Biopharm. 2008;70(2):500-505.

6. Alsarra IA, Alanazi FK, Ahmed SM, et al. Comparative study of itraconazole-cyclodextrin inclusion complex and its commercial product. Arch Pharm Res. 2010;33(7):1009-1017.

7. Lee SY, Jung II, Kim JK, Ryu JH. Preparation of itraconazole/ HP-beta-CD inclusion complexes using supercritical aerosol solvent extraction system and their dissolution characteristics. J Supercrit Fluids. 2008;44(3):400-408.

8. Park YJ, Xuan JJ, Oh DH, et al. Development of novel itraconazoleloaded solid dispersion without crystalline change with improved bioavailability. Arch Pharm Res. 2010;33(8):1217-1225.

9. Piao ZZ, Choe JS, Oh KT, Rhee YS, Lee BJ. Formulation and in vivo human bioavailability of dissolving tablets containing a selfnanoemulsifying itraconazole solid dispersion without precipitation in simulated gastrointestinal fluid. Eur J Pharm Sci. 2014;51:67-74.

10. Van Eerdenbrugh B, Van Speybroeck M, Mols R, et al. Itraconazole/ TPGS/Aerosil (R) 200 solid dispersions Characterization, physical stability and in vivo performance. Eur J Pharm Sci. 2009;38(3) 270-278.

11. Kapsi SG, Ayres JW. Processing factors in development of solid solution formulation of itraconazole for enhancement of drug dissolution and bioavailability. Int J Pharm. 2001;229(1-2):193-203.

12. Park JH, Chi SC, Lee WS, et al. Toxicity studies of cremophor-free paclitaxel solid dispersion formulated by a supercritical antisolvent process. Arch Pharm Res. 2009;32(1):139-148.

13. Jung JY, Yoo SD, Lee SH, Kim KH, Yoon DS, Lee KH. Enhanced solubility and dissolution rate of itraconazole by a solid dispersion technique. Int J Pharm. 1999;187(2):209-218.

14. Duret C, Wauthoz N, Sebti T, Vanderbist F, Amighi K. Solid dispersions of itraconazole for inhalation with enhanced dissolution, solubility and dispersion properties. Int J Pharm. 2012;428(1-2):103-113.

15. Yang M, He S, Fan Y, et al. Microenvironmental $\mathrm{pH}$-modified solid dispersions to enhance the dissolution and bioavailability of poorly watersoluble weakly basic GT0918, a developing anti-prostate cancer drug: preparation, characterization and evaluation in vivo. Int J Pharm. 2014; 475(1-2):97-109.

16. Bae SK, Park SJ, Shim EJ, et al. Increased oral bioavailability of itraconazole and its active metabolite, 7-hydroxyitraconazole, when co-administered with a vitamin $\mathrm{C}$ beverage in healthy participants. J Clin Pharmacol. 2011;51(3):444-451.
17. Agrawal AM, Dudhedia MS, Patel AD, Raikes MS. Characterization and performance assessment of solid dispersions prepared by hot melt extrusion and spray drying process. Int J Pharm. 2013;457(1): 71-81.

18. Kim EJ, Chun MK, Jang JS, Lee IH, Lee KR, Choi HK. Preparation of a solid dispersion of felodipine using a solvent wetting method. Eur J Pharm Biopharm. 2006;64(2):200-205.

19. Lin SP, Hou YC, Liao TY, Tsai SY. Enhancing the bioavailability of magnolol in rabbits using melting solid dispersion with polyvinylpyrrolidone. Drug Dev Ind Pharm. 2014;40(3):330-337.

20. Muehlenfeld C, Kann B, Windbergs M, Thommes M. Solid dispersion prepared by continuous cogrinding in an air jet mill. J Pharm Sci. 2013; 102(11):4132-4139.

21. Zhang Z, Chen Y, Deng J, Jia X, Zhou J, Lv H. Solid dispersion of berberine-phospholipid complex/TPGS 1000/SiO2: preparation, characterization and in vivo studies. Int J Pharm. 2014;465(1-2):306-316.

22. Won DH, Kim MS, Lee S, Park JS, Hwang SJ. Improved physicochemical characteristics of felodipine solid dispersion particles by supercritical anti-solvent precipitation process. Int J Pharm. 2005; 301(1-2):199-208.

23. Kim MS, Kim JS, Park HJ, Cho WK, Cha KH, Hwang SJ. Enhanced bioavailability of sirolimus via preparation of solid dispersion nanoparticles using a supercritical antisolvent process. Int J Nanomedicine. 2011;6:2997-3009.

24. Shanmugam S, Park JH, Chi SC, Yong CS, Choi HG, Woo JS. Physicochemical stability, pharmacokinetic, and biodistribution evaluation of paclitaxel solid dispersion prepared using supercritical antisolvent process. Drug Dev Ind Pharm. 2011;37(6):628-637.

25. Li Y, Yang DJ, Chen SL, Chen SB, Chan AS. Comparative physicochemical characterization of phospholipids complex of puerarin formulated by conventional and supercritical methods. Pharm Res. 2008;25(3):563-577.

26. Sethia S, Squillante E. Solid dispersion of carbamazepine in PVPK30 by conventional solvent evaporation and supercritical methods. Int J Pharm. 2004;272(1-2):1-10.

27. Lee S, Nam K, Kim MS, et al. Preparation and characterization of solid dispersions of itraconazole by using aerosol solvent extraction system for improvement in drug solubility and bioavailability. Arch Pharm Res. 2005;28(7):866-874.

28. Sathigari SK, Ober CA, Sanganwar GP, Gupta RB, Babu RJ. Singlestep preparation and deagglomeration of itraconazole microflakes by supercritical antisolvent method for dissolution enhancement. J Pharm Sci. 2011;100(7):2952-2965.

29. Rehman M, Shekunov BY, York P, et al. Optimisation of powders for pulmonary delivery using supercritical fluid technology. Eur J Pharm Sci. 2004;22(1):1-17.

30. Herberger J, Murphy K, Munyakazi L, Cordia J, Westhaus E. Carbon dioxide extraction of residual solvents in poly(lactide-co-glycolide) microparticles. J Control Release. 2003;90(2):181-195.

31. Jourdil JF, Tonini J, Stanke-Labesque F. Simultaneous quantitation of azole antifungals, antibiotics, imatinib, and raltegravir in human plasma by two-dimensional high-performance liquid chromatography-tandem mass spectrometry. J Chromatogr B Analyt Technol Biomed Life Sci. 2013;91(9-920):1-9.

32. Nagy ZK, Balogh A, Démuth B, et al. High speed electrospinning for scaled-up production of amorphous solid dispersion of itraconazole. Int J Pharm. 2015;480(1-2):137-142.

33. Matteucci ME, Paguio JC, Miller MA, Williams RO 3rd, Johnston KP. Highly supersaturated solutions from dissolution of amorphous itraconazole microparticles at pH 6.8. Mol Pharm. 2009;6(2):375-385. 


\section{Publish your work in this journal}

Drug Design, Development and Therapy is an international, peerreviewed open-access journal that spans the spectrum of drug design and development through to clinical applications. Clinical outcomes, patient safety, and programs for the development and effective, safe, and sustained use of medicines are a feature of the journal, which

has also been accepted for indexing on PubMed Central. The manuscript management system is completely online and includes a very quick and fair peer-review system, which is all easy to use. Visit http://www.dovepress.com/testimonials.php to read real quotes from published authors.

Submit your manuscript here: http://www.dovepress.com/drug-design-development-and-therapy-journal 